\title{
Polar Radar for Ice Sheet Measurements
}

\author{
Sivaprasad Gogineni, Glenn Prescott, David Braaten, Chris Allen and the PRISM Research Team \\ Radar and Remote Sensing Laboratory \\ Information and Telecommunication Technology Center \\ University of Kansas, Lawrence, KS 66045 \\ www.ittc.ku.edu
}

\begin{abstract}
We report on the PRISM research project currently underway at the University of Kansas - a multidisciplinary effort sponsored by the National Science Foundation and NASA. The objective of this project is to develop and deploy an innovative sensor system for measuring key glaciological parameters and studying the acquired data to understand the contributions of polar ice sheets to sea level rise. This project involves research in autonomous vehicles (i.e., rovers), intelligent systems, sounding radars and ice sheet modeling. When completed, we anticipate that the data collected and experience gained will make a substantial contribution to the long-term science goal of predicting ice sheet response to climate change, while advancing fundamental knowledge in the design, implementation and operation of distributed autonomous systems and self-sufficient computing.
\end{abstract}

Keywords-component; polar ice sheets, SAR, sea-level rise; sounding radar, rovers, autonomous systems.

\section{INTRODUCTION}

The sea level has been rising over the last century. Although the immediate impact of sea level rise may be less severe than other effects of global climate change, the longterm consequences can be much more devastating since nearly $60 \%$ of the world population lives in coastal regions. Scientists have postulated that excess water is being released from polar ice sheets due to long-term, global climate change, but there are insufficient data to confirm these theories. Accurate determination of the mass balance - net gain or loss of ice - of these ice sheets is an essential prerequisite to quantifying their role in the sea level rise. Satellites with altimeters-NASA's ICESAT and ESA's Cryosat - are scheduled to be launched in the next few years to monitor surface elevation of polar ice sheets to determine their mass balance shifts. This monitoring generates a requirement for process studies to characterize mass balance components to understand and model any satellite-observed changes and to predict the magnitude and nature of future changes. Our research addresses the measurement of mass balance components and seeks to establish an understanding of the internal, dynamic processes that control them. The prime enabler in this research is the innovative application of information technology in intelligent radar sensors for measuring key glaciological parameters.

\section{OBJECTIVES OF THE PROJECT}

This project aims to design and develop intelligent radar sensors for polar ice sheet measurements and demonstrate their scientific applicability. The primary sensors consist of a synthetic aperture radar (SAR) that can operate in bistatic or monostatic mode, and a wideband, dual-mode radar. The SAR is used to generate two-dimensional reflectivity maps of the bed for determining basal conditions, including the presence and distribution of basal water. The wideband, dual-mode radar measures ice thickness and maps internal layers in both shallow and deep ice. Data collected with the wideband radar on near-surface internal layers will be used to estimate the average, annual ice accumulation rate.

The sensors will be integrated into a complete information system consisting of two vehicles - an automated rover and a base (tracked) vehicle. These vehicles will be configured with the necessary communication and navigation systems to collect data from the sensors and route it back to a central location for further processing, analysis or storage. The bistatic/monostatic SAR and one dual-mode radar will be operated on the tracked vehicle. The SAR and another dualmode radar will be operated on the automated rover. In the bistatic configuration the SAR on the rover will be configured as a receiver. The onboard intelligent system will determine optimum sensor configuration using information derived from combined data sets generated by fusing real time data with that from satellite and aircraft sensors.

\section{SCIENCE OBJECTIVES}

This project is aimed at developing and demonstrating technology for measuring ice sheet boundary conditions, such as accumulation rate and the internal, dynamic processes that control ice sheet mass balance. This requires observations that include: ice thickness, depth and shape of internal layers, subglacial topography, and basal conditions (e.g., roughness, presence and configuration of subglacial water). Science requirements are summarized in Table 1.

Most of these requirements are achievable with the sensors we are developing. However, measurement of basal water layer thickness is a high risk requirement, and measurement of wet or frozen base requires more study.

Observations will concentrate on selected study areas where specific processes can be investigated. For example, major outlet glaciers in Greenland and Ice Stream D in Antarctica are changing rapidly and provide excellent opportunities to 
monitor the response of inland transition zones to these changes. Results from these locations will be analyzed to yield measurements of ice thickness, internal layer geometry and depth, bedrock and surface geometry, and basal conditions. Because the basal conditions and the internal properties of the two ice sheet locations are expected to be different, the first step will be a cross comparison of data as part of a sensitivity analysis. Once that is complete and the data validated against other available ancillary data, the geophysical products will be used by the science team first in order to refine estimates of the local ice sheet mass balance. Existing information on surface velocity will be incorporated into models of ice velocity with depth that are, in turn, based on measured basal conditions. The results will also be used to test flow models along flow lines where the bed changes from frozen to wet. This result alone is expected to yield considerable insight into where and why ice streams originate and how they might be expected to migrate.

The resulting information collected will be examined in the context of ice dynamics and mass balance in conjunction with ice models. We need to understand and be able to predict ice sheet mass balance - net growth or shrinkage - to quantify that contribution to present and future changes in sea level. Understanding the reasons for ice motion change and thinning is central to predicting future changes in ice sheet mass, and a key to this understanding will be quantitative knowledge of processes taking place deep in the ice. Therefore this project focuses on measuring and modeling subsurface, glaciological processes. Observational objectives include:

- Define glacier three-dimensional geometry and quantify driving stresses.
- Measure internal layering in shallow ice to compute temporal and spatial variability in ice accumulation (snowfall), and in deep ice to give a history of past glacier deformation and provide crucial validation of theoretical models.

- Measure basal conditions, whether the bed is wet or frozen, and determine the mode of glacier flow.

This last objective stands out as a major gap in knowledge about the boundary conditions governing glacier motion and is an observational requirement that has eluded all previous technologies.

Once measurements have been completed, we will develop a hierarchy of models to incorporate the measurements into a predictive capability. Initially, we will develop geophysical models of the glacier bed interaction based on current data and theory. These models will be used to refine the measurement and system technical requirements and serve as a basis for analysis algorithms to be applied to the data later. Data collected with the system will then be used to develop models of specific processes with the ice sheet. Models will be developed for the onset of streaming flow and the behavior of the inland ice sheet as the boundary between streaming and slow flow migrates. Existing models will also be validated. For example, thermodynamical ice sheet models have been used to predict where the bed is frozen and where meltwater resides under the ice, and these predictions can be compared with the rover measurements as verification. Internal layering offers another opportunity for model validation as these layers represent isochrones whose depth can be predicted from the three-dimensional velocity field. Finally, models of specific, local processes will be incorporated into drainage-basin-scale models of ice sheet behavior.

TABle 1 SCIEnCE MeAsurement REQUIREMENTS

\begin{tabular}{|c|c|c|c|c|}
\hline $\begin{array}{c}\text { Measured Ice } \\
\text { Parameter }\end{array}$ & $\begin{array}{c}\text { Relevance to } \\
\text { Science Obj. * }\end{array}$ & $\begin{array}{l}\text { Required } \\
\text { Accuracy }\end{array}$ & Spatial Sampling & Sensor \\
\hline Ice thickness & 1,2 & $5 \mathrm{~m}$ & $\begin{array}{l}100 \text { m survey } \\
10 \text { m hi-res }\end{array}$ & wideband depth sounder \\
\hline Wet or frozen base & 3 & $95 \%$ confidence & $100 \mathrm{~m}$ pixel & $\begin{array}{c}\text { monostatic and } \\
\text { bistatic SAR }\end{array}$ \\
\hline $\begin{array}{c}\text { Basal water layer } \\
\text { thickness }\end{array}$ & 3,4 & $\begin{array}{l}50 \% \text { or better } \\
4 \mathrm{~mm} \text { to } 0.5 \mathrm{~m}\end{array}$ & $\begin{array}{c}100 \mathrm{~m} \text { survey } \\
10 \mathrm{~m} \text { hi-res }\end{array}$ & $\begin{array}{c}\text { monostatic and } \\
\text { bistatic SAR }\end{array}$ \\
\hline $\begin{array}{c}\text { Internal layer depth } \\
\text { and geometry }\end{array}$ & $5,2,6$ & $\begin{array}{c}10 \mathrm{~cm} @ \text { surface } \\
5 \mathrm{~m} @ \text { base }\end{array}$ & $\begin{array}{l}100 \mathrm{~m} \text { survey } \\
10 \mathrm{~m} \text { hi-res }\end{array}$ & wideband depth sounder \\
\hline Bottom topography & 2 & $5 \mathrm{~m}$ & $\begin{array}{l}100 \mathrm{~m} \text { survey } \\
10 \mathrm{~m} \text { hi-res }\end{array}$ & wideband depth sounder \\
\hline Surface topography & 2 & $0.5 \mathrm{~m}$ & $\begin{array}{l}100 \mathrm{~m} \text { survey } \\
10 \mathrm{~m} \text { hi-res }\end{array}$ & $\begin{array}{c}\text { In SAR, Radar/Laser } \\
\text { Altimeter, GPS }\end{array}$ \\
\hline Surface velocity & $1,2,6$ & $\begin{array}{c}5 \% \text { in speed } \\
5 \mathrm{deg} \text { in direction }\end{array}$ & $500 \mathrm{~m}$ grid & $\begin{array}{c}\text { interferometric SAR } \\
\text { (RADARSAT-1 or ERS-1) }\end{array}$ \\
\hline
\end{tabular}




\section{TECHNOLOGY OBJECTIVES}

Our approach to meeting this project's scientific objectives is to develop an instrumented rover that will function in conjunction with a tracked vehicle to execute key measurements over polar ice sheets. We are developing one autonomous rover with radars to generate two-dimensional images of the ice-bed interface, measure ice thickness, and map internal layers in deep ice with modest resolution and internal layers in shallow ice with high resolution. We will design this system with sufficient autonomy and intelligence so that it can operate for extended periods with little human intervention.

To accomplish our scientific objectives, our research objectives are:

- $\quad$ Develop a three-frequency Monostatic and Bistatic Synthetic Aperture Radar (M/B SAR) for acquiring data to determine ice sheet basal conditions unambiguously.

- Develop a dual-mode radar for high-resolution mapping of near-surface internal layers (to hundreds of meters), and to measure ice thickness and map deeper internal layers to a depth of several kilometers.

- Develop a single ice-sheet-capable autonomous vehicle for radar measurements

- Develop near real time intelligent information/image analysis system to dynamically select "optimum" sensor configuration.

- Develop control capabilities for sustaining the sensor system, collecting and processing data, and transmitting it to a central archive.

- Integrate vehicles and sensors and evaluate the integrated systems at a test site in the Continental US.

- Collect data over test sites in Antarctica and Greenland to demonstrate the operation of the sensor system and its ability to measure key geophysical variables.

- Develop numerical electromagnetic and geophysical models of ice sheets to specify sensors and interpret measured data.

\section{PROJECT IMPLEMENTATION}

During initial development, we will test and evaluate sensors and an automated rover at the summit of the Greenland ice sheet. After completely integrating the sensors and automated vehicles, we will conduct experiments in Greenland and Antarctica to demonstrate the utility of intelligent radar sensors in collecting ice sheet data.

Figure 1 shows the conceptual implementation of our approach for collecting key geophysical data. The rover will contain a data/signal processor, communications transceiver, Global Positioning System (GPS) receiver, and two radars: a monostatic/ bistatic synthetic aperture radar (M/B SAR) for detailed mapping and a dual-mode wideband radar for determining ice thickness.

The system collects data with the dual-mode wideband radar operated as a depth sounder. It analyzes these data to determine ice thickness and bed characteristics. It then uses analysis results in conjunction with a priori information, for example from RADARSAT and other image data, to decide the optimum radar configuration for imaging the bed.

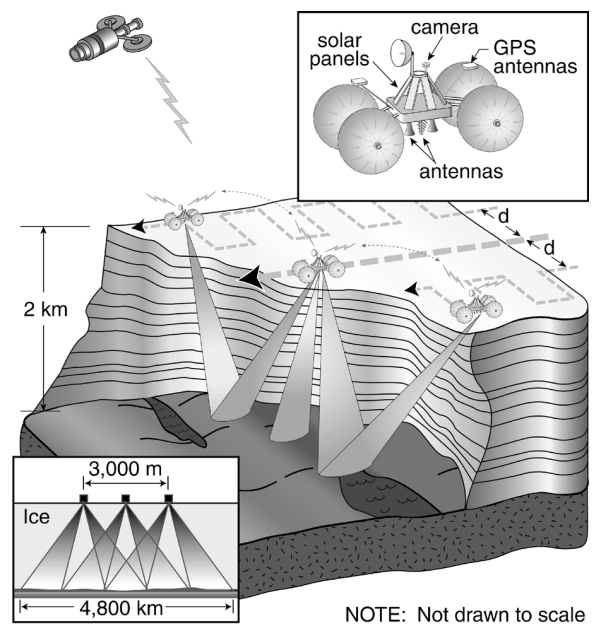

Figure 1. Conceptual implementation of the approach for radar imaging with $\mathrm{M} / \mathrm{B}$ SAR. Inset shows cross-sectional view of monostatic mode

\section{ACKNOWLEDGMENTS}

Funding for the PRISM project is provided by the National Science foundation and NASA. The PRISM team consists of Sivaprasad Gogineni (PI), Arvin Agah, Chris Allen, David Braaten, Victor Frost, Jennifer Holvoet, Glenn Prescott, and Costas Tsatsoulis

\section{REFERENCES}

Complete information of the PRISM project including a library of reports, papers and presentations can be found at: www.ku-prism.org 